\title{
Increased Ribavirin Bioavailability Associated With Telaprevir Use in Hepatitis C Patients Treated With PEGylated -Interferon/Ribavirin/Telaprevir Triple Therapy
}

\author{
Pierre Pradat ${ }^{1,2,3,} ;$ :Victor Virlogeux ${ }^{1,4}$; Marianne Maynard ${ }^{1,2,3}$; Mathilde Leclercq ${ }^{1}$; Giorgiana \\ Hatu $^{1,5}$; Majid Amiri ${ }^{1}$; Fanny Lebosse ${ }^{1,2,3}$; Patrick Miailhes ${ }^{6}$; Fabien Zoulim ${ }^{1,2,3,7}$; Marie-Claude \\ Gagnieu $^{8}$; François Bailly ${ }^{1,2,3}$ \\ ${ }^{1}$ Department of Hepatology, Croix-Rousse Hospital, Hospices Civils of Lyon, Lyon, France \\ ${ }^{2}$ National Institute of Health and Medical Research (INSERM) U1052, Lyon, France \\ ${ }^{3}$ Claude Bernard Lyon 1 University, Lyon, France \\ ${ }_{5}^{4}$ Ecole Normale Superieure, Lyon, France \\ 5 University of Medicine and Pharmacy, Cluj-Napoca, Romania \\ 6 Department of Infectious Diseases and Tropical Medicine, Hospices Civils de Lyon, Lyon, France \\ ${ }_{8}^{7}$ Institut Universitaire of France, Paris, France \\ 8 Department of Pharmacology, Edouard Herriot Hospital, Hospices Civils de Lyon, Lyon, France \\ ${ }^{*}$ Corresponding Author: Pierre Pradat, Department of Hepatology, Croix-Rousse Hospital, Hospices Civils of Lyon, Lyon, France. Tel: +33-426732715, Fax: +33-426732734, \\ E-mail: pierre.pradat@univ-lyon1.fr
}

Received: March 30, 2015; Revised: March 31, 2015; Accepted: June 30, 2015

Background: Anemia is more frequent in patients receiving telaprevir with PEGylated interferon/ribavirin (PEG-IFN/RBV) than in those receiving PEG-IFN/RBV alone.

Objectives: The objective was to measure the impact of telaprevir on RBV bioavailability and to assess the concomitant renal function. Materials and Methods: Thirty-seven hepatitis C virus (HCV) patients non-responders to a previous course of PEG-IFN/RBV therapy and re-treated with triple therapy combining PEG-IFN/RBV and telaprevir were analyzed. RBV bioavailability was measured before the triple therapy initiation, during telaprevir treatment at week (W) 4 and W8, and after telaprevir cessation (post W16). The renal function was assessed by estimating the glomerular filtration rate (eGFR).

Results:AtW4, RBVbioavailability, expressed as $\mathrm{mg} / \mathrm{L} /$ daily dose/kg body weight, was significantly increased (median increase $=0.06 \mathrm{mg} / \mathrm{L} /$ dose $/ \mathrm{kg} ; \mathrm{P}<0.001)$. In parallel, the renal function was impaired with a mean eGFR decrease of $-6.8 \mathrm{~mL} / \mathrm{minutes} / 1.73 \mathrm{~m}^{2}(\mathrm{P}=0.109)$. Between W4 and W8, RBV bioavailability continued to increase $(\mathrm{P}<0.001)$ but subsequently decreased slightly after telaprevir discontinuation with a concomitant restoration of the renal function (eGFR increase of $6.34 \mathrm{~mL} /$ minutes $/ 1.73 \mathrm{~m}^{2}$ ).

Conclusions: Our results indicated a reversible increase in RBV bioavailability after telaprevir exposure, which might be linked to the impairment of the GFR. This also suggests a RBV-telaprevir pharmacological interaction, a possible source of severe anemia observed under triple therapy. These results suggest that RBV pharmacological monitoring may be clinically relevant, especially in the context of first-generation HCV protease inhibitor-based therapy.

Keywords: Anemia; Antiviral Agents; Glomerular Filtration Rate; Hepatitis C; Ribavirin; Telaprevir

\section{Background}

Before the arrival of new direct-acting antiviral agents (DAAs), triple therapy combining PEGylated interferon (PEG-IFN), ribavirin (RBV), and protease inhibitors (boceprevir or telaprevir) was the standard of care for the treatment of hepatitis $C$ virus (HCV) infection (1-4).

Anemia is commonly observed during RBV-based therapy and often results in dose reduction and decreased antiviral efficacy. Because of a large inter-individual variability in exposure (5-7), the weight-based RBV daily dose is poorly correlated with the RBV plasma concentration
(8). Previous studies have indicated that anemia is about twice more frequent in patients receiving telaprevir with PEG-IFN/RBV than in those receiving PEG-IFN/RBV alone (9).

\section{Objectives}

The objective of this study was to determine whether telaprevir-based therapy was associated with an increased RBV plasma exposure, which could in part explain the increased incidence of anemia. In parallel, we studied the impact of telaprevir on the renal function. 


\section{Materials and Methods}

\subsection{Patients}

HCV patients with a previous non-response to PEG-IFN/ RBV therapy and re-treated with PEG-IFN/RBV and telaprevir were prospectively recruited from the department of hepatology, Croix-Rousse hospital, Lyon, France. Non-response was defined as a failure to achieve a sustained virological response and could thus include null response, virological breakthrough, and virological relapse. Patients with decompensated liver cirrhosis were not included. Patients were selected if they had consecutive assessment of plasma RBV trough concentrations (prescribed at the clinician's discretion). Baseline was considered as the date of triple therapy initiation. Patients with chronic kidney disease (CKD) stage 4 (estimated glomerular filtration rate (eGFR) $<30 \mathrm{~mL} /$ minutes $/ 1.73 \mathrm{~m}^{2}$ ) were excluded from the study.

\subsection{Assessment of Plasma Ribavirin Concentration}

Plasma RBV trough concentrations were measured using a validated high-performance liquid chromatography-diode array detector method (10). This method is highly specific, sensible (limit of quantification = $0.05 \mathrm{mg} / \mathrm{L}$ ), and precise (total imprecision, calculated by measuring the coefficient of variation of the internal quality control values, was $<10 \%$ for concentrations from 0.20 - $5.00 \mathrm{mg} / \mathrm{L}$ ). Plasma RBV trough concentrations were measured before telaprevir initiation during the previous course of PEG-IFN/RBV combination therapy (T-1), during the early phase (week (W) $4 \pm 2$ weeks), the later phase (W $8 \pm 2$ weeks), and after telaprevir cessation (at least 4 weeks after telaprevir withdrawal (W16)).

As RBV daily doses may vary among patients and during the study course, RBV exposure was calculated using the ratio concentration/dose/body weight and used as a mean of estimated inter-individual bioavailability.

\subsection{Renal Function Assessment}

The commonly used Modification of the Diet in Renal Disease (MDRD) study equation was used for the eGFR as follows: in males: $186 \times(\text { creatinine } \times 0.0113)^{-1.154} \times$ age $^{-0.203}$. If the patient was of African origin or female, multiplicative factors of 1.21 and 0.742 were applied, respectively. The occurrence of renal insufficiency during treatment was defined as an eGFR $<60 \mathrm{~mL} /$ minutes $/ 1.73 \mathrm{~m}^{2}$.

\subsection{Statistical Analysis}

The nominal and categorical parameters were expressed as absolute numbers and percentages. Means and standard deviations ( \pm SD) were calculated for the normally distributed variables, and medians and interquartile ranges (IQR) for the skewed variables.
The non-parametric test for paired data (Wilcoxon test) was used to analyze the variations in RBV bioavailability and the eGFR before, during, and after triple therapy.

A P value $<0.05$ was considered statistically significant. All the analyses were performed using Statistical Package for the Social Sciences (SPSS), version 19.0 for Windows (SPSS Inc., Chicago, Illinois, USA).

\subsection{Ethical Consideration}

All the patients included in this study gave their written inform consent to allow the use of their personal clinical data in accordance with the ethics regulation defined in France by the CNIL (Commission Nationale de l'Informatique et des Libertés).

\section{Results}

The data on 37 consecutive HCV patients initiating triple therapy were analyzed. The patients' characteristics are presented in Table 1 . Male gender was predominant (73.0\%), and mean age was 56.5 years ( \pm 10.7$)$. Thirty-one per cent of the patients were cirrhotics, among whom $18 \%$ had some sign of decompensation. Three (8.1\%) patients had renal insufficiency defined as $30<$ eGFR $<60 \mathrm{~mL} /$ minutes $/ 1.73 \mathrm{~m}^{2}$ (CKD stage 3 ). One patient with severe renal insufficiency (eGFR $<30 \mathrm{~mL} /$ minutes $/ 1.73 \mathrm{~m}^{2}$ ) was excluded from the analysis.

A significant increase in RBV bioavailability was observed between $\mathrm{T}-1$ and $\mathrm{W} 4(\mathrm{~N}=37,0.06 \pm 0.09 \mathrm{mg} / \mathrm{L} / \mathrm{dose} /$ $\mathrm{kg} ; \mathrm{P}<0.001)$. This increase was even stronger between $\mathrm{T}-1$ and $\mathrm{W} 8(\mathrm{~N}=20,0.18 \pm 0.21 \mathrm{mg} / \mathrm{L} / \mathrm{dose} / \mathrm{kg} ; \mathrm{P}<0.001)$. A significant increase was also observed between $\mathrm{W} 4$ and W8 $(\mathrm{N}=20,0.11 \pm 0.17 \mathrm{mg} / \mathrm{L} /$ dose $/ \mathrm{kg} ; \mathrm{P}<0.001)$.

Among these patients, 13 had measures of RBV bioavailability before, during, and after triple therapy. In this subgroup of patients, similar results were observed with an increase after telaprevir initiation $(0.08 \pm 0.10 \mathrm{mg} / \mathrm{L} /$ dose $/$ $\mathrm{kg}$ between $\mathrm{T}-1$ and $\mathrm{W} 4 ; \mathrm{P}=0.017$ and $0.07 \pm 0.12 \mathrm{mg} / \mathrm{L} /$ dose/kg between W4 and W8; $\mathrm{P}=0.012)$. A decrease in bioavailability, albeit non-significant, was observed after telaprevir cessation (-0.03 $\pm 0.14 \mathrm{mg} / \mathrm{L} /$ dose $/ \mathrm{kg}$ between W8 and W16; $\mathrm{P}=0.839$ ) (Figure 1). Eleven patients had a RBV dose reduction between $\mathrm{W} 4$ and $\mathrm{W} 8$, and all of them still increased their RBV bioavailability despite a reduced plasma concentration in five of them.

None of the following factors was predictive of the variations in RBV bioavailability: gender $(\mathrm{P}=0.837)$; IL-28B genotype $(\mathrm{P}=0.630)$; cirrhosis versus non cirrhosis $(\mathrm{P}=0.414)$; fibrosis stage $(\mathrm{P}=0.858)$; HCV genotype 1a versus $1 \mathrm{~b}(\mathrm{P}=0.937)$; and body mass index (BMI) $(\mathrm{P}=0.436)$, and nor was the eGFR at baseline associated with RBV bioavailability $(\mathrm{P}=0.527)$. Only age was significantly associated with a higher increase in RBV bioavailability in the older patients $(\mathrm{P}=0.011)$.

In parallel to these variations, the eGFR was evaluated. A decrease in the eGFR was observed between T-1 and W4 $\left(\mathrm{N}=37,-6.8 \pm 25.21 \mathrm{~mL} /\right.$ minutes $\left./ 1.73 \mathrm{~m}^{2} ; \mathrm{P}=0.109\right)$ and an increase after telaprevir cessation in the subgroup of 13 
Pradat P et al.

\begin{tabular}{|c|c|c|}
\hline Characteristics & Number of Patients & Values $^{\mathrm{a}}$ \\
\hline Male gender & 37 & $27(73.0)$ \\
\hline Hepatitis C virus genotype & 34 & \\
\hline $1 \mathrm{a}$ & & $7(20.6)$ \\
\hline $1 \mathrm{~b}$ & & $13(38.2)$ \\
\hline 1 undetermined & & $9(26.5)$ \\
\hline 2 & & $2(5.9)$ \\
\hline 4 & & $3(8.8)$ \\
\hline Genotype IL-28B & 14 & \\
\hline $\mathrm{C} / \mathrm{C}$ & & $4(28.6)$ \\
\hline $\mathrm{T} / \mathrm{C}$ & & $4(28.6)$ \\
\hline $\mathrm{T} / \mathrm{T}$ & & $6(42.8)$ \\
\hline Presence of diabetes & 37 & $4(11.8)$ \\
\hline Presence of renal insufficiency ${ }^{b}$ & 37 & $3(8.1)$ \\
\hline Fibrosis stage & 35 & \\
\hline Fo/F1 & & $11(31.4)$ \\
\hline F2 & & $2(5.8)$ \\
\hline F3 & & $11(31.4)$ \\
\hline F4 & & $11(31.4)$ \\
\hline Body mass index, $\mathrm{kg} / \mathrm{m}^{2}$ & 21 & $24.8 \pm 3.0$ \\
\hline Age, $y$ & 37 & $56.5 \pm 10.7$ \\
\hline
\end{tabular}

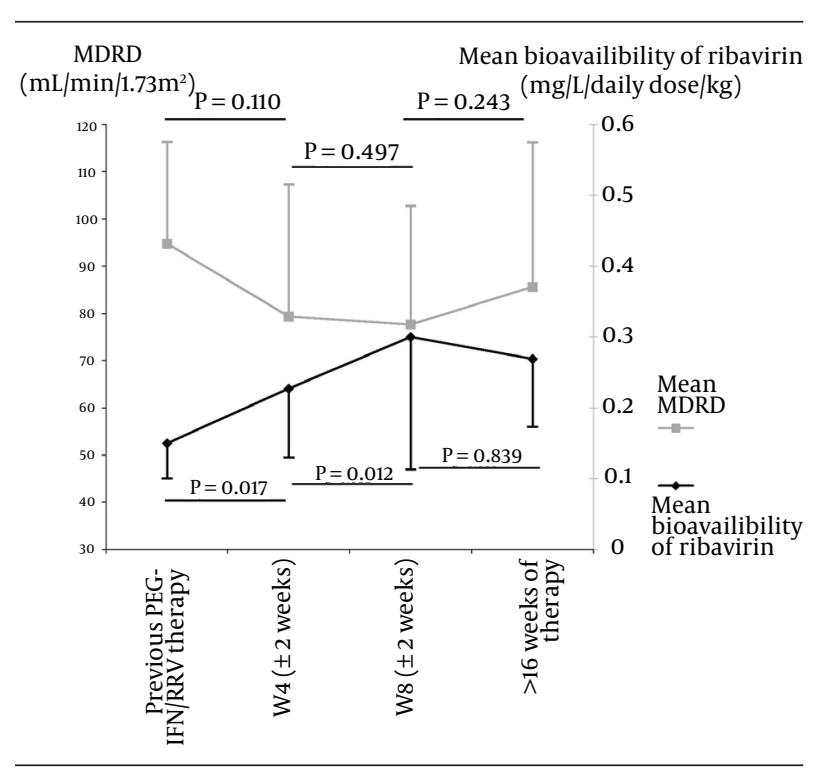

Figure 1. Mean Ribavirin Bioavailability and Estimated Glomerular Filtration Rate Assessed by MDRD Before, During, and After Telaprevir Exposure in Hepatitis C Virus Patients Treated With PEGylated Interferon/Ribavirin/ Telaprevir Combination patients (6.34 $\pm 23.7 \mathrm{~mL} / \mathrm{minutes} / 1.73 \mathrm{~m}^{2} ; \mathrm{P}=0.243$ ) (Figure 1).

When comparing between three different groups of patients characterized by their eGFR at T-1 (i.e. eGFR < $60,60-90$, and $>90 \mathrm{~mL} /$ minutes $/ 1.73 \mathrm{~m}^{2}$, respectively), the group of patients with an initial eGFR $>90$ was associated with the most important decrease in the eGFR between T-1 and W4 compared with the other two groups $(\mathrm{P}<0.001)$. No significant difference in the mean RBV bioavailability increase was observed between these three groups $(\mathrm{P}=0.555)$.

Anemia was also assessed during the different phases of therapy. A significant decrease in the hemoglobin level was observed between T-1 and $\mathrm{W} 4(\mathrm{~N}=36,12.4 \pm 22.9 \mathrm{~g} / \mathrm{L} ; \mathrm{P}=$ $0.004)$ and also between $\mathrm{W} 4$ and $\mathrm{W} 8(\mathrm{~N}=20,8.5 \pm 18.8 \mathrm{~g} / \mathrm{L} ; \mathrm{P}$ $=0.09)$. However, no significant variations were observed between W8 and W16 for the subgroup of 13 patients.

\section{Discussion}

The assessment of RBV bioavailability measures the actual exposure to RBV, whereas the trough plasma con- 
centration varies with posology. RBV bioavailability is known to range between $45 \%$ and $65 \%$ with an important variability within and between individuals, which can reach $30 \%$ after an oral single dose (11). Equilibrium state is reached after 4 weeks of multiple dosing and the halflife is 300 hours. Our results showed that during triple therapy, RBV bioavailability was significantly increased after the introduction of telaprevir irrespective of the variations in the RBV doses. This increase was progressive throughout exposure to telaprevir. After the cessation of the HCV protease inhibitor, a 4-week period was necessary to observe a decrease in RBV bioavailability. In parallel to these variations, the eGFR also seemed to have been impaired by telaprevir. Recently, some authors have shown in HIV-HCV coinfected patients that telaprevir enhances RBV-induced anemia through renal function impairment (12). Telaprevir was already known to play a role in the inhibition of renal drug transporter in the in vitro system (13). In HEK 293 cell lines, telaprevir exposure seems to result in the inhibition of the organic cation transporter 2 (OCT2) and of the multidrug and toxin extrusion (MATE)-type transporter 1 (MATE1) (14). This mechanism could explain the eGFR decrease in patients treated with telaprevir, which in turn is a risk factor for anemia (15). RBV-induced anemia is thought to result from molecular mechanisms such as the inhibition of intracellular energy metabolism and oxidative membrane damage (16). It is thus possible that renal dysfunction due to HCV protease inhibitor increases RBV exposure, thereby inducing anemia.

Our study, including 37 patients, was possibly underpowered to detect potential associations between RBV bioavailability and co-factors such as gender, BMI, and other clinical factors. In a previous study, Jen et al. (6) reported associations between the RBV apparent clearance and body weight, gender, and age and showed that the RBV apparent clearance was increased among the patients with a higher BMI and among the males, but decreased among the patients above 40 years of age. This latter observation is in accordance with our results, showing a higher increase in RBV bioavailability in the older patients. A more recent study also showed that among the HCV genotype 2/3 patients treated with PEG-IFN/RBV, obesity (BMI > 30) was associated with lower RBV concentrations (17). Similar findings were reported by Wade et al. (18), who observed that lean body weight was the only covariate with a clinically significant influence on RBV pharmacokinetics and that RBV exposure decreased as weight increased.

In the present study, we did not include data on albumin, bilirubin, or prothrombin time, involved in the hepatocellular function. However, various studies have demonstrated that the liver function has no effect on the RBV concentration (19-21).

Although conducted on a limited number of patients, our study clearly shows a reversible increase in RBV exposure during telaprevir treatment, which might be linked to the impairment of the eGFR. This also suggests a RBVtelaprevir pharmacological interaction, a possible source of severe anemia observed under triple therapy and already reported in HCV-monoinfected (22) or HIV-HCV coinfected cirrhotic patients (23). The persistence of a high RBV exposure despite RBV dose reductions recommended for severe anemia could explain why these dose reductions do not impact the virological response. As recently suggested, RBV pharmacological monitoring may still be clinically relevant even in the context of direct-acting antiviralsbased therapy $(24,25)$. This monitoring, potentially followed by RBV dose adaptations, could ensure an optimal RBV exposure, thereby improving safety and reducing the relapse risk. Cautious clinical monitoring of patients focusing not only on hematological parameters but also on the renal function is warranted.

\section{Acknowledgements}

The authors gratefully thank the Hospices Civils de Lyon for funding this study.

\section{Authors' Contributions}

Study concept and design: Pierre Pradat, Marianne Maynard, Fabien Zoulim, Marie Claude Gagnieu, and Francois Bailly. Acquisition of data: Marianne Maynard, Majid Amiri, Fanny Lebosse, Patrick Miailhes, Fabien Zoulim, Francois Bailly, and Marie Claude Gagnieu. Analysis and interpretation of data: Victor Virlogeux, Mathilde Leclercq, Giorgiana Hatu, Pierre Pradat, Marianne Maynard, Marie Claude Gagnieu, and Francois Bailly. Drafting of the manuscript: Victor Virlogeux, Giorgiana Hatu, and Pierre Pradat. Critical revision of the manuscript for important intellectual content: Pierre Pradat, Victor Virlogeux, Marianne Maynard, Mathilde Leclercq, Giorgiana Hatu, Majid Amiri, Fanny Lebosse, Patrick Miailhes, Fabien Zoulim, Marie Claude Gagnieu, and Francois Bailly. Statistical analysis: Victor Virlogeux and Pierre Pradat. Study supervision: Francois Bailly and Fabien Zoulim.

\section{Funding/Support}

The study was funded and hosted by the Hospices Civils de Lyon.

\section{References}

1. Bacon BR, Gordon SC, Lawitz E, Marcellin P, Vierling JM, Zeuzem $\mathrm{S}$, et al. Boceprevir for previously treated chronic HCV genotype 1 infection. N Engl J Med. 2011;364(13):1207-17.

2. Jacobson IM, McHutchison JG, Dusheiko G, Di Bisceglie AM, Reddy $\mathrm{KR}$, Bzowej NH, et al. Telaprevir for previously untreated chronic hepatitis C virus infection. NEngl J Med. 2011;364(25):2405-16.

3. Poordad F, McCone JJ, Bacon BR, Bruno S, Manns MP, Sulkowski MS, et al. Boceprevir for untreated chronic HCV genotype 1 infection. N Engl J Med. 2011;364(13):1195-206.

4. Zeuzem S, Andreone P, Pol S, Lawitz E, Diago M, Roberts S, et al. Telaprevir for retreatment of HCV infection. $N$ Engl J Med. 2011;364(25):2417-28.

5. Glue P. The clinical pharmacology of ribavirin. Semin Liver Dis 1999;19 Suppl 1:17-24. 
6. Jen JF, Glue P, Gupta S, Zambas D, Hajian G. Population pharmacokinetic and pharmacodynamic analysis of ribavirin in patients with chronic hepatitis C. Ther Drug Monit. 2000;22(5):555-65.

7. Larrat S, Stanke-Labesque F, Plages A, Zarski JP, Bessard G, Souvignet C. Ribavirin quantification in combination treatment of chronic hepatitis C. Antimicrob Agents Chemother. 2003;47(1):124-9.

8. Jen J, Laughlin M, Chung C, Heft S, Affrime MB, Gupta SK, et al. Ribavirin dosing in chronic hepatitis C: application of population pharmacokinetic-pharmacodynamic models. Clin Pharmacol Ther. 2002;72(4):349-61.

9. Sitole M, Silva M, Spooner L, Comee MK, Malloy M. Telaprevir versus boceprevir in chronic hepatitis C: a meta-analysis of data from phase II and III trials. Clin Ther. 2013;35(2):190-7.

10. Sauvage FL, Stanke-Labesque F, Gagnieu MC, Jourdil JF, Babany G, Marquet P. Feasibility of ribavirin therapeutic drug monitoring in hepatitis C. Ther Drug Monit. 2009;31(3):374-81.

11. Preston SL, Drusano GL, Glue P, Nash J, Gupta SK, McNamara P. Pharmacokinetics and absolute bioavailability of ribavirin in healthy volunteers as determined by stable-isotope methodology. Antimicrob Agents Chemother. 1999;43(10):2451-6.

12. Cotte L, Barrail-Tran A, Vincent C, Valantin MA, Fournier I, Lacombe K, et al. Telaprevir enhances ribavirin-induced anaemia through renal function impairment. Antivir Ther. 2015.

13. Kunze A, Huwyler J, Camenisch G, Gutmann H. Interaction of the antiviral drug telaprevir with renal and hepatic drug transporters. Biochem Pharmacol. 2012;84(8):1096-102.

14. Meyer zu Schwabedissen HE, Verstuyft C, Kroemer HK, Becquemont L, Kim RB. Human multidrug and toxin extrusion 1(MATE1 SLC47A1) transporter: functional characterization, interaction with OCT2 (SLC22A2), and single nucleotide polymorphisms. Am JPhysiol Renal Physiol. 2010;298(4):F997-F1005.

15. Borroni G, Cazzaniga M, Andreoletti M, Ceriani R, Guerzoni P, Omazzi B, et al. Low glomerular filtration rate is a risk factor for ribavirin-associated anaemia in old patients with chronic hepatitis C. JViral Hepat. 2013;20(4):e90-5.

16. Russmann S, Grattagliano I, Portincasa P, Palmieri VO, Palasciano
G. Ribavirin-induced anemia: mechanisms, risk factors and related targets for future research. Curr Med Chem. 2006;13(27):3351-7.

17. Alsio A, Rembeck K, Askarieh G, Christensen PB, Farkkila M Langeland N, et al. Impact of obesity on the bioavailability of peginterferon-alpha2a and ribavirin and treatment outcome for chronic hepatitis C genotype 2 or 3. PLoS One. 2012;7(5):e37521.

18. Wade JR, Snoeck E, Duff F, Lamb M, Jorga K. Pharmacokinetics of ribavirin in patients with hepatitis $\mathrm{C}$ virus. $\mathrm{Br} J$ Clin Pharmacol. 2006;62(6):710-4

19. European Medicines Agency. Summary of Product Characteristics. European Medicines Agency; 2015. Available from: http://www. ema.europa.eu/docs/en_GB/document_library/EPAR_-_Product_Information/human/000246/WC500048210.pdf.

20. Glue P, Schenker S, Gupta S, Clement RP, Zambas D, Salfi M. The single dose pharmacokinetics of ribavirin in subjects with chronic liver disease. BrJClin Pharmacol. 2000;49(5):417-21.

21. Takaki S, Tsubota A, Hosaka T, Akuta N, Someya T, Kobayashi M, et al. Factors contributing to ribavirin dose reduction due to anemia during interferon alfa $2 \mathrm{~b}$ and ribavirin combination therapy for chronic hepatitis C. J Gastroenterol. 2004;39(7):668-73.

22. Hezode C, Fontaine H, Dorival C, Zoulim F, Larrey D, Canva V, et al. Effectiveness of telaprevir or boceprevir in treatment-experienced patients with HCV genotype 1 infection and cirrhosis. Gastroenterology. 2014;147(1):132-142 e4.

23. Miailhes P, Gilbert C, Lacombe K, Arends JE, Puoti M, Rockstroh JK, et al. Triple therapy with boceprevir or telaprevir in a European cohort of cirrhotic HIV/HCV genotype 1-coinfected patients. Liver Int. 2015.

24. Brochot E, Bodeau S, Duverlie G. Does therapeutic drug monitoring of ribavirin in HCV genotype 3 treatment with sofosbuvir and ribavirin still have a role? Ther Drug Monit. 2015;37(4):550-1.

25. Pradat P, Virlogeux V, Gagnieu MC, Zoulim F, Bailly F. Ribavirin at the Era of Novel Direct Antiviral Agents for the Treatment of Hepatitis C Virus Infection: Relevance of Pharmacological Monitoring. Adv Hepatol. 2014;2014:1-13. 